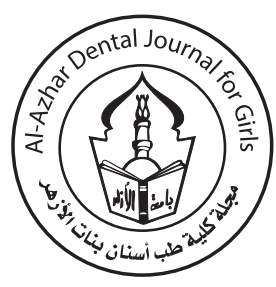

\title{
Evaluation of Anticarcinogenic Potential of Broccoli Extract on Oral Squamous Cell Carcinoma Cell Line
}

\author{
Doaa A. Habba ${ }^{1 *}$, Nadia A. Radi ${ }^{2}$, Eman A. Abo Hager ${ }^{3}$
}

Codex : 11/22.01

azhardentj@azhar.edu.eg

http://adjg.journals.ekb.eg

DOI: $10.21608 /$ adjg.2021.47114.1309

Oral Medicine \& Surgical Sciences (Oral Medicine, Oral \& Maxillofacial Surgery, Oral Pathology, Oral Biology)

\begin{abstract}
Purpose: The current research was conducted to estimate the anticarcinogenic effect of sulforaphane (SFN) combined with different doses of the chemotherapeutic agent cisplatin(CIS) on the cell line of Squamous cell carcinoma orally to consider sulforaphane (Broccoli extract) Outcome on cell viability and apoptosis of the oral squamous cell carcinoma cell line. Subjects and Method: Squamous cell carcinoma of the human tongue (SCC9) cell line subcultured to obtain 6 study groups, which were subjected to SFN, CIS with low dose, CIS with high dose and a combination of both (SFN with CIS in low concentration $=\operatorname{mix} 1$ and SFN with CIS in high concentration $=\operatorname{mix} 2$ ), one study group of SCC9, not subjected to therapy, was used as a negative control. Using Doses of both SFN, CIS were determined using the MTT viability assay, to calculate their IC50 value. Then, apoptotic analysis, using Caspase3, in different study groups were assessed using RT-PCR. Results: Treatment results have been measured for cell viability, apoptosis and gene expression. In dose- and a time- dependent way, SFN decreased viability for SCC9 cells. SFN-combined therapy increased CIS cytotoxic activity because low-dose CIS (mix1) SFN was extremely cytotoxic to SCC9 after 72 hours. SFN increased SCC9 apoptosis with a high dose of CIS (mix2) and that process was due to up-regulation of Caspase3. Conclusion: Cytotoxicity against SCC9 cells was increased by combining SFN with low doses of CIS. In the treatment of OSCCC, combined SFN-CIS mixtures have a possible additive mean.
\end{abstract}

\section{INTRODUCTION}

Researchers have disclosed that the burden of cancer is based on the latest projections of cancer incidence and mortality worldwide, an unprecedented rise in speed and stressed aimed at urgent introduction of
Squamous Cell Carcinoma, Sulforaphane, Cisplatin

* Paper extracted from Doctor of philosophy Thesis titled "Evaluation of Anticarcinogenic Potential of Broccoli Extract on Oral Squamous Cell Carcinoma Cell Line"

1. Assistant Lecturer of Oral and Dental Pathology, Faculty of Dental Medicine for Girls, Al Azhar University, Cairo, Egypt.

2. Associate Professor of Oral and Dental Pathology, Faculty of Dental Medicine for Girls, Al Azhar University, Cairo, Egypt.

3. Professor of Oral and Dental Pathology, Faculty of Dental Medicine for Girls, Al Azhar University, Cairo, Egypt.

* Corresponding author email: doaahabba.26@azhar.edu.eg 
new, effective treatment methods and techniques for prevention the current global social and economic transitions indicate an increasing cancer burden over the next decades, especially in the next few decades ${ }^{(1)}$. Oral squamous cell carcinoma (OSCC) constitutes $80-90 \%$ of all neck and head tumor in oral cavity and oropharynx. Oral cancer may affect the tongue, mouth floor, buccal surface, alveolar surface and hard palate. The most common subsite is the tongue, which is one of the worst subsites in terms of prognosis ${ }^{(2)}$.

The use of cancer cell lines allowed an increase in the information about the defected genes and signaling pathways in this disease. Furthermore, the use of an appropriate in vitro model in cancer research in crucial. It's required for the investigation of genetic, epigenetic and cellular pathways, for the study of proliferation, apoptosis and cancer progression to define potential molecular markers and for the screening and characterization of cancer therapeutics ${ }^{(3)}$. Resistance to traditional surgical, radiation, chemical treatments tends to be a limiting factor when treating SCCHN. The efficacy of current standard chemotherapy, such as CIS, is one significant factor in the failure of cancer care, is partially limited because of its extreme toxic adverse reactions. CIS forms DNA adduct which lead to induction of apoptosis in cancer cells ${ }^{(4)}$. The serious side effects of treatment with CIS is skin toxicity, nephrotoxicity, bone marrow suppression with hemolytic anemia and neurotoxicity that affect both cancer and non-cancer (normal) cells. Reducing the chemotherapeutic dose while maintaining its efficacy is critical to improve the treatment outcome of cancers and to decrease morbidity and mortality rates ${ }^{(5)}$.

Over the past few years, chemo-preventing cancer with normal products, phytochemicals present in different edible and non-edible medicinal plants have gained significant attention in particular ${ }^{(6)}$. SFN is the greatest common isothiocyanate composite, present in cruciferous vegetables at elevated concentrations, such as broccoli ${ }^{(7)}$. Such vegetables are a good source of health-promoting compounds and actually protect phytochemicals, including vitamins $\mathrm{C}$ and $\mathrm{E}$, carotenoids, chlorophylls, phenolic compounds and isothiocyanate ${ }^{(8)}$. SFN is one of the plant-derived organosulfur isothiocyanate compounds most commonly studied and is present in cruciferous vegetables, such as broccoli, at high concentrations ${ }^{(7)}$. Broad range of biological effects have been documented, including antioxidants, antimicrobials, anticancer agents ${ }^{(9)}$, anti-inflammatory agents, anti-aging agents ${ }^{(10)}$, neuroprotective agents and anti-diabetics ${ }^{(11)}$. The toxicity of SFN is low ${ }^{(12)}$, making it an attractive candidate as a chemotherapy agent. When used in conjunction with other anticancer compounds, it has been revealed that SFN targets many passageways involved in growth cell functions. Exactly, SFN increased the impact of imatinib on myeloid chronic leukemia cells, gemcitabine on cells for pancreatic cancer ${ }^{(13,14)}$. The antioxidant capacity of SFN, however, encouraged the appearance of phase 2 metabolic enzymes capable of cells protection against ROS ${ }^{(15)}$. SFN inhibits the progression of cell cycles, induces apoptotic cell death, and inhibits ovarian and colon cancer angiogenesis and metastasis ${ }^{(16)}$. Using the caspase-based pathway, SFN induced apoptosis by elevated Casp3 appearance through increasing BAX and decreasing BCL2 ${ }^{(17)}$.

There are few studies to date investigating the anticarcinogenic function of broccoli extract in oral squamous cell carcinoma. This research will therefore concentrate on understanding this function and researching the value of using the natural product in combination with a chemical anticancer drug to take advantage of reducing its dosage and preventing its side effects on the body.

\section{MATERIAL AND METHODS}

\section{Cell culture}

SCC9 was purchased from American Type Culture Collection (ATCC) through Innovation Lab, VACSERA and Cairo, Egypt. SCC9 is tongue squa- 
mous cell carcinoma cell line ${ }^{(18,19)}$. It was held at (-1960C) in a liquid nitrogen container. The cell lines (stored in cryotubes) were removed from the bottle of liquid nitrogen and thawed immediately at $37 \mathrm{oC}$ in a water bath. It was cultivated in RPMI 1640 improved with $10 \%$ foetal calf serum (FCS), Biowalker purchased Phosphate buffer saline (PBS) and imported by Maadi Medical Supplies, $2 \%$ sodium bicarbonate and 2\% antibiotic (Streptomycin Penicillin)-antifungal agent (Nystatin). The cell line was incubated at $37^{\circ} \mathrm{C}$ with 5 per cent $\mathrm{CO}_{2}$ in a humidified incubator. Culture flasks were studied under the inverted phase contrast microscope to ensure viability, sterility and adequacy for cultured cells.

\section{Cytotoxic agents}

Sulforaphane (Munich, Germany) was purchased from Sigma Aldrich as a solution in ethanol with purity $\geq 90 \%, 5 \mathrm{mg}$ and stored at $-20{ }^{\circ} \mathrm{C}$. Cisplatin was purchased from Sigma Aldrich and dissolved in DMSO to make stock solutions. Final concentrations of DMSO in the working solution medium were $0.05 \%$.

\section{MTT assay}

One ml of cells (50,000 to 100,000 cells / ml) was put for 24 hours in each well of the 96- plate culture. The cells have been protected in a $\mathrm{CO} 2$ incubator for $24 \mathrm{hrs}$. Later treatment of cells by antibiotic and antifungal agents for $24-72 \mathrm{~h}$, experimental media were extracted and cells were washed in PBS. Different concentrations of SFN and CIS were treated and further incubated for $24 \mathrm{~h}, 48 \mathrm{~h}$ and $72 \mathrm{~h}$. Sigma Aldrich (3-(4, 5-Dimethylthiazol-2-yl)-2, 5-Diphenyltetrazolium Bromide) (10\% solution of $0.5 \mathrm{mg} /$ $\mathrm{ml}$ MTT in medium) was then extracted, additional to both well, keep warm for $4 \mathrm{~h}$ at $37^{\circ} \mathrm{C}$. By adding DMSO to each well, the medium was removed and formazan was disbanded. Visual thickness calculated at $570 \mathrm{~nm}$ in a Flx 800 Microplate Reader (BIO-TEK Instruments, Vermont, United States). In triplicates, test remained completed.

\section{Evaluation of Caspase 3 levels of interpretation by real-time quantitative PCR (QPCR)}

To distinguish alterations the Caspase 3 coding genes, QPCR was used. In the treatment of cells, higher drug doses have been used to illustrate the impact of management on genomic levels. Total RNA was take out from SCC9 cells preserved with or without SFN using TRIzol (Thermo Fisher Scientific) for $24 \mathrm{~h}, 48 \mathrm{~h}, 72 \mathrm{~h}$, with or without CIS. The first-strand cDNA was synthesised with the HighCapacity cDNA Reverse Transcription Kit (Thermo Fisher Scientific) from $1 \mu \mathrm{g}$ total RNA. In the incidence of PowerUp SYBR Green Master Mix (Thermo Fisher Scientific), QPCR was achieved consuming the StepOnePlus TM Real-Time PCR Way (Thermo Fisher Scientific) for the quantification of gene strengthening. Glyceraldehyde-3-phosphate dehydrogenase (GAPDH) was secondhand as the endogenous countenance standard. Mark arrangements were better at $95^{\circ} \mathrm{C}$ for $10 \mathrm{~min}$, followed by 40 cycles of $95{ }^{\circ} \mathrm{C}$ for $15 \mathrm{~s}$ and $60-65^{\circ} \mathrm{C}$ annealing temperature for each gene for $1 \mathrm{~min}$. The following gene-specific primers were used: GAPDH: (5'-GCA AGT TCA ACG GCA CGA TCA AG-3'). (5'- CTA CTC AGC ACC AGC ATC ACC-3'). Caspase3:(5'CTCGGTCTGGTACAGATGTCGA-3').(5'CATGGCTCAGAAGCACACAAAC-3'). Both experiments carried out in triplicate, appearance determined on the source of the process of Ct. In accordance with the method of $2^{\wedge} \Delta \Delta \mathrm{CT}$., the fold shift in Caspase 3 expression was calculated ${ }^{(20)}$.

\section{Analysis of statistics}

Data were represented as median, range, mean and standard deviation (SD) values. Kruskal-Wallis test was used to compare between the groups as well as the time periods. Dunn's test was used for pair-wise comparisons when Kruskal-Wallis test is significant. The significance level was set at $\mathrm{P} \leq$ 0.05 . Statistical analysis was performed with $\mathrm{IBM}^{\circledR}$ ( ${ }^{\circledR} \mathrm{IBM}$ Corporation, NY, USA) SPSS ${ }^{\circledR}\left({ }^{\circledR}\right.$ SPSS, Inc., an IBM Company) Statistics Version 23 for Windows. 


\section{RESULTS}

\section{Morphological assessment:}

Under inverted phase microscope, cells were examined on a regular basis to ensure their viability. After treatment with sulforaphane, cisplatin and a mixture of both agents, the cancer cells showed features of apoptosis. Shrinkage, clumping of DNA and apoptotic bodies include these (fig., 1, A, B).

\section{Statistical results:}

\section{Cell viability percentage:}

A statistically significant difference was found between IC50 levels at various time intervals $(\mathrm{P}$-value $=0.039),(\mathrm{P}$-value $=0.027),(\mathrm{P}$-value $=0.027)$ and $(\mathrm{P}$-value $=0.031)$ for cisplatin, sulforaphane, mix 1 and mix 2 classes, respectively.
Comparisons of time intervals in pairs found that there was no statistically significant alteration between 48 hours, 72 hours; equally revealed a statistically slightly lesser IC50 median than 24 hours (Table 1, fig., 2).

\section{Determination of apoptosis:}

There was a statistically significant difference among Caspase 3 fold shifts at various time intervals $(\mathrm{P}$-value $=0.032)$ and $(\mathrm{P}$-value $=0.046)$ through respect to Cisplatin low dose and Cisplatin high dose classes. Comparisons in pairs between the time ranges revealed that there was no statistically significant change between 48 hours, 72 hours; equally exhibited a statistically significantly greater mean shift in Caspase 3 fold than 24 hours. (Table 2, fig., 3).

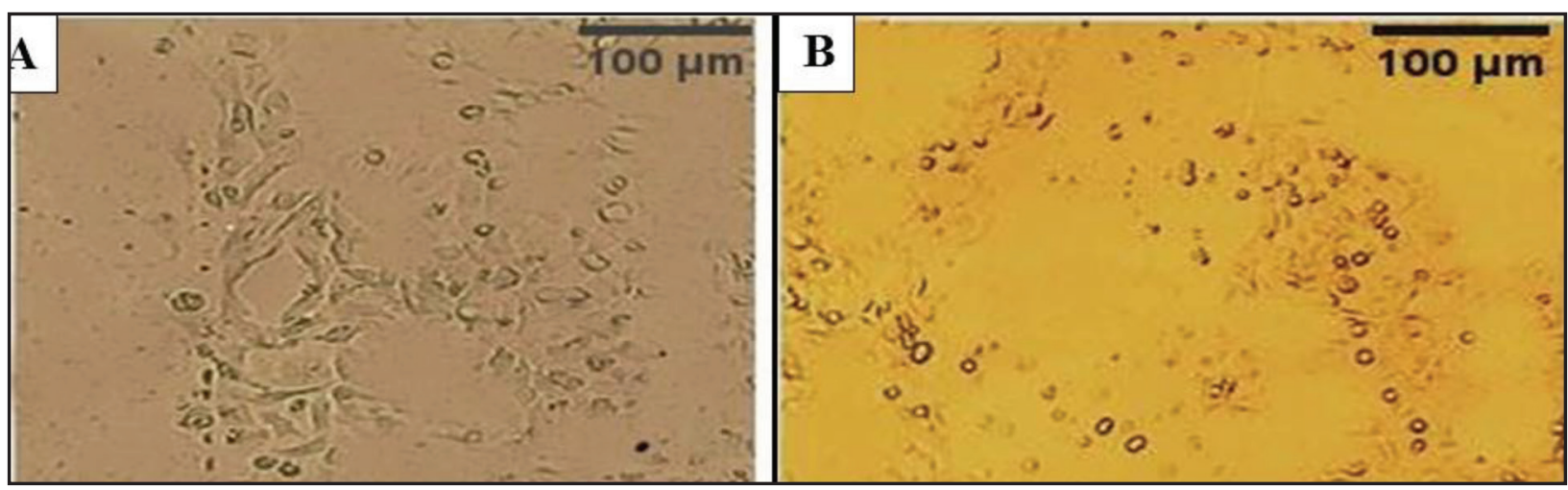

Figure (1) Inverted phase microscope photomicrograph showing decrease in number of viable cells and change cells shape through many cells undergoing apoptosis after addition of (Mix1 at 72h), (SFN at 48h) treated groups (A,B x200).

Table (1) Comparison between IC50 levels at different time periods within each group by Kruskal-Wallis test.

\begin{tabular}{|c|c|c|c|c|c|c|c|}
\hline \multirow{2}{*}{ Group } & \multicolumn{2}{|c|}{24 hours } & \multicolumn{2}{|c|}{48 hours } & \multicolumn{2}{|c|}{72 hours } & \multirow[b]{2}{*}{ P-value } \\
\hline & Median & Range & Median & Range & Median & Range & \\
\hline Cisplatin & $5^{\mathrm{A}}$ & $4.8-5.2$ & $1.2^{\text {в }}$ & $0.8-1.5$ & $0.7^{\text {в }}$ & $0.4-0.9$ & $0.039^{*}$ \\
\hline Sulforaphane & $14.5^{\mathrm{A}}$ & $13-16$ & $4^{\text {в }}$ & $3.8-4.2$ & $1.5^{\mathrm{B}}$ & $1.2-1.7$ & $0.027 *$ \\
\hline Mix 1 & $8.5^{\mathrm{A}}$ & $8.1-8.9$ & $2.4^{\mathrm{B}}$ & $2-2.8$ & $0.4^{\mathrm{B}}$ & $0.4-0.5$ & $0.027^{*}$ \\
\hline Mix 2 & $5.1^{\mathrm{A}}$ & $4.7-5.3$ & $1.3^{\text {в }}$ & $0.9-1.6$ & $0.8^{\text {в }}$ & $0.8-0.9$ & $0.031 *$ \\
\hline
\end{tabular}

* Different superscripts in the same row are statistically significantly different from each other at $P \leq 0.05$. 
Table(2) Relationship among Caspase 3 fold changes at different time periods within each group by Kruskal-Wallis test.

\begin{tabular}{|c|c|c|c|c|c|c|c|}
\hline \multirow{2}{*}{ Group } & \multicolumn{2}{|c|}{24 hours } & \multicolumn{2}{|c|}{48 hours } & \multicolumn{2}{|c|}{72 hours } & \multirow{2}{*}{ P-value } \\
\hline & Median & Range & Median & Range & Median & Range & \\
\hline Cisplatin low dose & $8.4^{\text {в }}$ & $7.2-9.5$ & $14.6^{\mathrm{A}}$ & $12.8-16.5$ & $17.3^{\mathrm{A}}$ & $16.5-18$ & $0.032 *$ \\
\hline Cisplatin high dose & $12^{\text {в }}$ & $10.8-13.1$ & $21.4^{\mathrm{A}}$ & $19.1-23.6$ & $21.2^{\mathrm{A}}$ & $20-22.5$ & $0.046^{*}$ \\
\hline Sulforaphane & $6.5^{\mathrm{C}}$ & $5.8-7.1$ & $14.5^{\text {в }}$ & $12.9-16$ & $24.1^{\mathrm{A}}$ & $22-26.3$ & $0.027 *$ \\
\hline Mix 1 & 15 & $13.6-16.5$ & 20.8 & $19.6-22$ & 20.5 & $19.2-21.9$ & 0.061 \\
\hline Mix 2 & $15.6^{\mathrm{C}}$ & $14.1-17$ & $23.9^{\mathrm{B}}$ & $22.6-25.2$ & $29.5^{\mathrm{A}}$ & $27.4-31.6$ & $0.027 *$ \\
\hline
\end{tabular}

* Different superscripts in the same row are statistically significantly different from each other at $P \leq 0.05$.

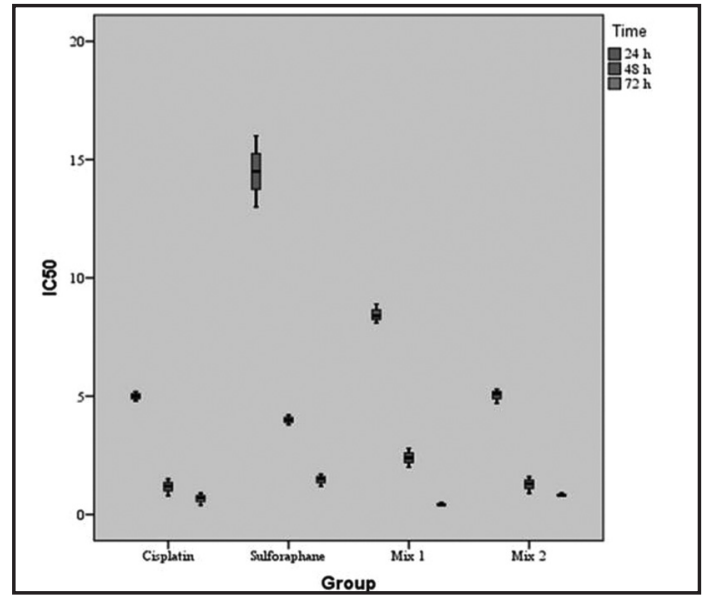

Figure (2) Box plot demonstrating median plus range standards for IC50 levels in the different groups (MTT cytotoxicity assay).

\section{DISCUSSION}

Squamous cell carcinoma of the head and neck is one of the most common malignant neoplasms. $60 \%$ cases treatment identified have cancers advanced that need collective modality healing, containing surgical treatment, radiotherapy, chemotherapy ${ }^{(21)}$. The restricted effectiveness of traditional chemotherapy due to its significant toxic side effects is one of the key reasons for the failure of cancer treatment. The method is reducing the dosage chemotherapeutic although preserving therapeutic success through the combination of CIS and the low-

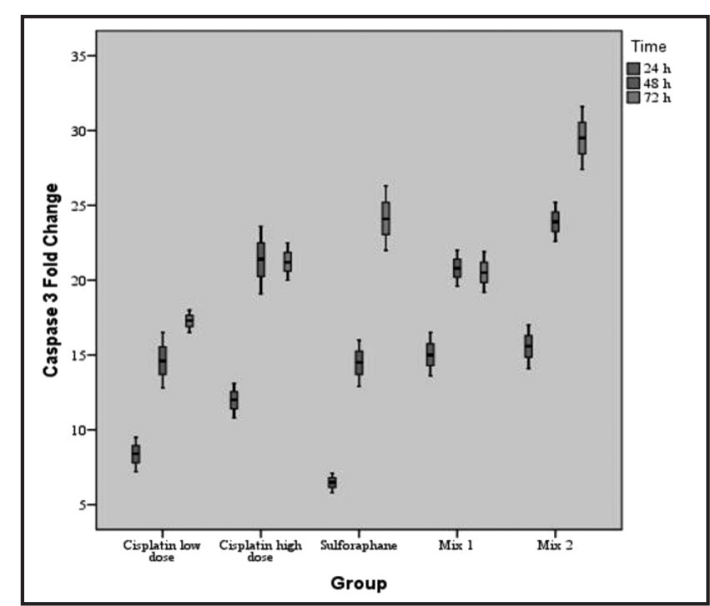

Figure (3) Box plot representing median and range values for Caspase 3 fold change in the different groups.

toxicity natural product SFN was thus addressed in this review. That is why, with such a disorder, there is a compelling need for innovative alternative treatments. Fortunately, the potential use of dietary components derived from fruits and vegetables has been indicated by several lines of evidence, as they have produced substantial results against oral cancer in the past few decades. Non-toxic and devoid of significant side effects, these naturally occurring bioactive dietary phytochemicals have made them attractive candidates for cancer treatment ${ }^{(22)}$.

Tongue cancer was the cell line of choice in 
the current research, as it has been reported to be the most commonly observed type of OSCC and is also the most commonly found in everyday practice ${ }^{(23)}$. Cell culture refers to a valuable tool for examinations in different fields and promotes the study of natural properties and processes that are not readily accessible in the unblemished living being dimension ${ }^{(24)}$.

The most successful resource for the future pharmaceutical agent was natural products. In achieving chemical diversity for human use, it was the scaffolds and characterized by anticancer properties ${ }^{(25)}$. SFN was chosen as the topic of the present research, since it was studied in various fields like cancer treatment and yielded promising results. While numerous studies showed anti-neoplastic effect of SFN against solid tumors such as breast, liver, brain, pancreatic, prostate and skin tumors has been reported. ${ }^{(26)}$. However, to the best of our understanding, in literature available, its result on OSCC has not been extensively studied. The potential anti-tumor impact of SFN on OSCC has been of interest in the current work for all of the abovementioned points.

It was very important to use a reference chemotherapeutic drug to compare its findings with those of the SFN groups judge beneficial consequence of SFN on OSCC. CIS has been selected as one of the greatest dynamic chemotherapeutic specialists in the cure of various malignant growth types and is typically paired with various operators, such as docetaxel, gemcitabine and 5-FU ${ }^{(27)}$. Be that as it may, its use is confined because of severe symptoms, for example, paleness, neurotoxicity, nephrotoxicity and the achievement of drug opposition ${ }^{(28)}$.

Regarding cytotoxicity in the current study. At $24 \mathrm{~h}$ and $48 \mathrm{~h}$, although CIS had the highest cytotoxic effect, there was no significant variance among CIS, Mix1 and Mix2 reflecting the synergistic effect of SFN on CIS. At $72 \mathrm{~h}$ combination of SFN and low dose of CIS (Mix1) showed the highest cytotoxic effect even more than CIS alone with no significant difference indicating that SFN has a potent cytotoxic effect improving the action of CIS in a time dependent manner, same results was reported earlier on studying HNSCC ${ }^{(29)}$.

Our findings showed that through increasing dosage and time, SFN decreased the viability of the OSCC cell lines. As the IC50 calculated after $72 \mathrm{~h}$ of care for SCC9 was very similar to acute lymphocytic leukemia, the SFN inhibitory effect on OSCC is comparable to other forms of cancers ${ }^{(30)}$. A Collective therapy is the safest treatment strategy of illness. The basic rule for mix chemotherapy is to use drugs that function through different mechanisms of action and this prompted diminish the advancement of healthy malignancy cells. This was explained by the researcher who said that the significance of blend treatments growing from free tools of operation that could restrict the advancement of drug opposition and provide adequate disease cell slaughter to treat a patient by transmitting these drugs to their most severe enduring part, a condition that could allow malignant growth cell executing to be improved ${ }^{(31)}$.

The viability results of the present study after 72h showed that Mix1 had a higher cytotoxic effect than SFN, CIS alone and Mix 2. We established this suggestion, we found that after $72 \mathrm{~h}$, SFN cotreatment reduced the viability of OSCC cells more than cisplatin alone $(\mathrm{P}<0.05)$. This increase in the cytotoxic result can be used to reduce the typical doses of CIS used for treatment in try, to reduce dosedependent side effects. Our results were comparable to those obtained using SFNN alongside other forms of tumors such as gastric carcinoma, pancreas, prostate cancers, head and neck cancers ${ }^{(27,29)}$. The findings of this study have shown that a combination of SFN and CIS is an efficient in vitro way of achieving synergistic anti-tumor effects against OSCC. Some preclinical studies indicate that CIS prevents cancer cell line proliferation ${ }^{(32)}$. Even, treatment with cisplatin alone is insufficient to cause cells to undergo apoptosis and has cytotoxic effects on cell growth in most tumors cell lines in general (33). Cisplatin, however, has been shown to increase 
the incidence of apoptosis in a variety of model systems in combination with natural products and other anticancer agents ${ }^{(34)}$.

Casp3 has been used in various studies as an indicator of apoptosis ${ }^{(35)}$. In the present study, the level of Casp3 was highest in the group receiving combination therapy, in comparison to the other study groups and this is matching with previous study ${ }^{(29)}$. In the current research, SFN combination therapy with CIS has been shown to exert an apoptotic and cytotoxic effect on SCC9. Thus, by using a lower dose of CIS, it produces promising results. More efficient strategies for eliminating side effects or tackling drug resistance have recently been investigated and have become the most significant problem in cancer care ${ }^{(36,37)}$.

Adverse effects after treatment with cisplatin are dose-related and are more severe at high doses; the intensity of adverse events is decreased by lowering the dose ${ }^{(38)}$. Skin toxicity is among the severe consequences of CIS medication. Nephrotoxicity and kidney failure have also been reported to be encountered following CIS treatment ${ }^{(39)}$. This property is therefore key with regard to the potential therapeutic application of this compound, since it is likely to produce fewer side effects than traditional therapies.

Conversely, in another study, the cytotoxic and antitumor activity of SFN with using H596 non small cell lung cancer cell line was investigated. However, SFN demonstrated cytotoxicity against both normal lung epithelial cells and lung cancer cells that was not considered in previous study. To reduce the toxic side effects of SFN, a lower concentration $(10 \mu \mathrm{M})$ was used, which showed a weaker anticancer effect. These results suggest carefully considering dose reduction to minimize side effects while encouraging therapeutic efficacy ${ }^{(40)}$. Accordingly, this study describe the possibility of using SFN as a complementary, replacement or adjuvant therapy for traditional cytotoxic therapies, having less toxicity and side effects.

\section{CONCLUSION}

SFN is effective however used alone or in combination with chemotherapy in treatment of OSCC in attempt to minimize its side effects.

\section{CONFLICT OF INTEREST}

None declared.

\section{FUNDING}

No funding was received for this study.

\section{REFERENCES}

1. Ferlay J, Colombet M, Soerjomataram I. Global and Regional Estimates of the Incidence and Mortality for 38 Cancers: GLOBOCAN. 2018; 4:50-102.

2. Bugshan A, Farooq I. Oral squamous cell carcinoma: Metastasis potentially associated malignant disorders, etiology and recent advancements in diagnosis. F1000Res. 2020; 9: 229-39.

3. Fitzmaurice C, Allen C, Barber M, Barregard L, Bhutta $\mathrm{Z}$, Brenner H, et al. Global, regional, and national cancer incidence, mortality, years of life lost, years lived with disability and disability- adjusted life-years for 32 cancer groups, 1990 to 2015: a systematic analysis for the Global Burden of Disease Study. JAMA Oncol. 2017; 3: 524- 48.

4. Szturz P, Cristina V, Bourhis J, Simon C, Vermorken J. Cisplatin Eligibility Issues and Alternative Regimens in Locoregionally Advanced Head and Neck Cancer: Recommendations for Clinical Practice. Front Oncol. 2019; 9: 464-75.

5. Aldossary SA. Review on Pharmacology of Cisplatin: Clinical Use, Toxicity and Mechanism of Resistance of Cisplatin. Biomed Pharmacol J. 2019; 12: 7-15.

6. Koh YC, Ho CT, Pan MH. Recent advances in cancer chemoprevention withphytochemicals. J Food Drug Anal. 2020; 28: 14-37.

7. Ghawi SK, Methven L, Niranjan K. The potential to intensify sulforaphane formation in cooked broccoli (Brassica oleracea var. italica) using mustard seeds (Sinapis alba). Food Chem. 2019; 138: 1734- 41.

8. Malaterre A, Remize F, Poucheret P. Fruits and vegetables, as a source of nutritional compounds and phytochemicals: Changes in bioactive compounds during lactic fermentation. Food Res. Int. 2018; 104:86-99. 
9. Amjad AI, Parikh RA, Appleman LJ, Hahm E-R, Singh SV. Broccoli-derived sulforaphane and chemoprevention of prostate cancer: from bench to bedside. Curr Pharmacol Rep. 2015; 1:382-90.

10. Sikdar S, Papadopoulou M, Dubois J. What do we know about sulforaphane protection against photoaging? J Cosmet Dermatol. 2016; 15:72-7.

11. Lv J, Bao S, Liu T, Wei L ,Wang D, Ye W, et al. Sulforaphane delays diabetes-induced retinal photoreceptor cell degeneration. Cell Tissue Res. 2020; 382:477- 86.

12. Herman-Antosiewicz A, Xiao H, Lew L, Singh V. Induction of $\mathrm{p} 21$ protein protects against sulforaphane-induced mitotic arrest in LNCaP human prostate cancer cell line. Mol Cancer Ther. 2017; 6: 1673-81.

13. Tortorella S, Royce G, Licciardi P, Karagiannis T. Dietary Sulforaphane in Cancer Chemoprevention: The Role of Epigenetic Regulation and HDAC Inhibition. Antioxid Redox Signal. 2015; 22: 1382- 424.

14. Cheng YM, Tsai CC, Hsu YC. Sulforaphane, a dietary isothiocyanate, induces $\mathrm{G} 2 / \mathrm{M}$ arrest in cervical cancer cells through cyclinB1 downregulation and GADD45 $\beta / C D C 2$ association. Int. J. Mol. Sci. 2016; 17; 1530-43.

15. Vanduchova A, Anzenbacher P, Eva A. Isothiocyanate from Broccoli, Sulforaphane, and Its Properties. J. Med. Food. 2019; 22: 1089- 90.

16. Zhang Z,Li C, Shang L, Zou R, Zhan Y, Bi B. Sulforaphane induces apoptosis and inhibits invasion in U251MG glioblastoma cells. Springerplus. 2016; 5:235- 47.

17. Cho NP, Han HS, Leem DH, Choi IS, Jung JY, Kim HJ, et al. Sulforaphane enhances caspase-dependent apoptosis through inhibition of cyclooxygenase- 2 expression in human oral squamous carcinoma cells and nude mouse xenograft model. Oral Oncol. 2017; 45: 654-60.

18. Macedo T, Elias S, Torres H, Silveira D. Cytotoxic Effect of Erythroxylum suberosum Combined with Radiotherapy in Head and Neck Cancer Cell Lines. Braz Dent J. 2016; 27: 108- 12 .

19. Lin Z, Sun L, Xie S, Zhang S. Chemotherapy-Induced Long Non-coding RNA 1Promotes Metastasis and ChemoResistance of TSCC via the Wnt/ $\beta$-Catenin Signaling Pathway. Mol Ther. 2018; 26: 1494- 507.

20. Verna E. More attention should be paid on the interpretation of gene expression data. World J Gastroenterol. 2015; 18: $3181-2$.
21. Pałasz P, Adamski L, Magdalena G, Starzynska A, Studniarek M. Contemporary Diagnostic Imaging of Oral Squamous Cell Carcinoma - A Review of Literature. Pol J Radiol. 2017; 82: 193-202.

22. Datema F, Ferrier M, Van der Schroeff M, Baatenburg de Jong R. Impact of comorbidity on short- term mortality and overall survival of head and neck cancer patients. Head Neck. 2016; 32: 728-36.

23. Brandizzi D, Gandolfo M, Velazco L, Cabrini R, Lanfranchi H. Clinical features and evolution of oral cancer: A study of 274 cases in Buenos Aires, Argentina. Med Oral Patol Oral Cir Bucal. 2018; 13: 544-8.

24. Cindy L, Cherly D. Basic cell culture protocols. Human press publication New Jersey USA. 2016; 1- 371.

25. Blowman K, Magalhães M, Lemos F, Cabral C, Pires M. Anticancer properties of essential oils and other natural products. eCAM. 2018; 1: 1-12.

26. Folkard D, Marlow G, Mithen F, Ferguson L. Effect of Sulforaphane on NOD2 via NF- $x$ B: implications for Crohn's disease. J. Inflamm. 2015; 12: 1-6.

27. Wang HM, Lin CY, Hsieh CH. Induction chemotherapy with dose-modified docetaxel, cisplatin, and 5-fluorouracil in Asian patients with borderline resectable or unresectable head and neck cancer. J Formos Med Assoc. 2017; 116: 185- 92.

28. Saba F, Mody D, Tan S, Gill H, Rinaldo A, Takes R, et al. Toxicities of systemic agents in squamous cell carcinoma of the head and neck (SCCHN); A new perspective in the era of immunotherapy. Crit Rev Oncol Hematol. 2017; 115: 50-8.

29. Elkashty O, Ashry R, Elghanam G, Pham H, Su X, Stegen $\mathrm{C}$, et al. Broccoli extract improves chemotherapeutic drug efficacy against head-neck squamous cell carcinomas. Medical Oncology. 2018; 35:124-34.

30. Lan H, Yuan H, Lin C. Sulforaphane induces p53-deficient SW480 cell apoptosis via the ROS-MAPK signaling pathway. Mol. Med. Rep. 2017; 16: 7796-7804.

31. Saputra E, Huang L, Chen Y, Kello L. Combination Therapy and the Evolution of Resistance: The Theoretical Merits of Synergism and Antagonism in Cancer. Cancer Res. 2018; 78: 2419-31.

32. Son DJ, Hong JE, Ban JO, Park JH, Lee HL, Hwang JY, et al. Synergistic inhibitory effects of cetuximab and cisplatin on human colon cancer cell growth via inhibition of the ERK-Dependent EGF receptor signaling pathway. BioMed Res Int. 2015; 2015: 397563-77. 
33. Madhulaxmi M, Iyer K, Periasamy R, Gajendran P, Lakshmi T. Role of cisplatin in oral squamous cell carcinoma - A review. J. Adv. Pharm. Educ. 2017; 7: 39- 42.

34. Le X, Hanna E. Optimal regimen of cisplatin in squamous cell carcinoma of head and neck yet to be determined. Ann Transl Med. 2018; 6:229 -34.

35. Pistritto G, Trisciuoglio D, Ceci C, Garufi A, Orazi G. Apoptosis as anticancer mechanism: function and dysfunction of its modulators and targeted therapeutic strategies. Aging. 2016; 8: 603-19.

36. Kerr C, Adhikary G, Grun D, George N, Eckert L. Combination cisplatin and sulforaphane treatment reduces proliferation, invasion, and tumor formation in epidermal squamous cell carcinoma. Mol. Carcinog. 2018; 57: 3-11.

37. Xu Y, Han X, Li Y, Min H, Zhao X, Zhang Y, et al.
Sulforaphane mediates glutathione depletion via polymeric nanoparticles to restore cisplatin chemosensitivity. ACS Nano. 2019; 13:13445 - 55 .

38. Liu H, Lee G, Lee I, Ahn T, Kim S. Effects of genistein on anti-tumor activity of cisplatin in human cervical cancer cell lines. Obstet Gynecol Sci. 2019; 62: 322-8.

39. Volarevic V, Djokovic B, Jankovic G, Harrell R, Fellabaum C, Djonov V, et al. Molecular mechanisms of cisplatin-induced nephrotoxicity: A balance on the knife edge between renoprotection and tumor toxicity. J. BioMed. Sci. 2019; 26: $1-25$.

40. Sun M, Shi Y, Dang U, Di Pasqua A. Phenethyl Isothiocyanate and Cisplatin Co-Encapsulated in a Liposomal Nanoparticle for Treatment of Non-Small Cell Lung Cancer. Mol. Pharmacol. 2019; 24: 801-12. 